\title{
Surge protection of low voltage systems and relevant standards
}

\begin{abstract}
This paper discusses the components and techniques of protecting low voltage systems from lightning generated electrical transients and the adequacy of International Standards in addressing the transient protection issues. Our analysis question the suitability of 8/20 हs test current impulse in representing characteristics such as the time derivative or the energy content of lightning currents. The 10/350 \&s test current impulse better represents the integrated effect of the energy content of impulse component and long continuing current. A new waveform is required to be specified for testing the ability of protective devices to respond to the fast leading edges of subsequent strokes that may come 100s of millisecond after the preceding stroke. The test voltage waveform 1.2 / 50 \&s should also be modified to test the response of protective devices for fast leading edges of induced voltage transients. A surge protective device that is tested for lightning transients may not be able to provide defense against other transients.
\end{abstract}

